\title{
Association of Optimism and Perceived Stress among Young Adults
}

\author{
Ritika Joshi $^{1 *}$, Pragya Joshi ${ }^{2}$
}

\section{ABSTRACT}

Optimism is a part of positive psychology which leads to better adaptive and coping skills and reduced stress level in an individual. The aim of the present research was to study the association of optimism and perceived stress among young adults. The sample consisted of 170 young adults ( 79 males and 91 females) within the age range of 18 to 25 years. Purposive sampling technique was employed for collecting the data. The Perceived stress scale-10 (PSS; Cohen, Kamarack \& Marmelstein, 1983) and Life Orientation Test- Revised (Scheir, Carver, \& Bridges, 1994) was used for measuring perceived stress and optimism respectively. Correlation and t-test was found using IBM SPSS software. Findings suggested that optimism was negatively correlated with perceived stress. Females were found to score significantly higher on perceived stress levels than males. While the gender difference in optimism level was reported to be insignificant. Future research needs to be conducted on the relationship between gender and levels of optimism.

Keywords: optimism, perceived stress, young adults, PSS-10, LOT-R
A $\mathrm{n}$ individual's physical, psychological and social wellbeing is influenced by their inclination towards life outcomes. Optimism plays a significant role in assessing one's overall wellbeing. The major concepts being studied are Optimism and Perceived stress.

\section{Optimism}

The significance of positive thinking in reducing and coping with stress has increased widely and extensively studied. Generally, optimism has been defined as the inclination towards expecting favourable outcomes in life. Optimism as defined by Scheier and Carver (1992) is a trait of personality or a dispositional characteristic consisting of positive attitude regarding the future and an anticipation of a favourable life outcome. People tending to interpret their problems as being controllable, temporary, and specific to one situation are regarded as optimistics, pessimists on the other hand, see their issues as uncontrollable, long-lasting, and generalised to various life facets.

\footnotetext{
${ }^{1}$ University Of Delhi, Department of applied psychology, Delhi, India

${ }^{2}$ University Of Delhi, Department of applied psychology, Delhi, India

*Corresponding Author
}

Received: June 11, 2021; Revision Received: June 22, 2021; Accepted: June 30, 2021

(C) 2021, Joshi R.\& Joshi P.; licensee IJIP. This is an Open Access Research distributed under the terms of the Creative Commons Attribution License (www.creativecommons.org/licenses/by/2.0), which permits unrestricted use, distribution, and reproduction in any Medium, provided the original work is properly cited. 
According to Abramson, Seligman and Teasdale (1978), explanatory styles ie. methods of interpreting or elucidating negative life events are developed by individuals. Why some individuals give up and some individuals carry on and win over tough situations is explained by explanatory styles.

The key role while dealing with stressful events depends on our beliefs about how things are likely to work out. Optimistic people can cope more effectively with stress and thus lower their likelihood for illness. A study concluded that optimists experienced less stress and depression. Moreover, they had increased social support and positively interpreted the stressful situation. (Brissette, Scheier, and Carver 2002). Optimists experience an additional positive mood which itself may pave a path towards a state of physiological resilience. Further optimism may encourage active and persevering coping efforts leading to improved psychological adjustments and health in a long-term perspective.

\section{Perceived stress}

One of the factors contributing towards optimism may be perceived stress. The definition of stress generally involves three components namely, cognitive appraisal, physiological responses and behavioural tendencies. This occurs while responding to a perceived disbalance among demands of the situation and the resources required to cope with them.

Stress involves a transaction between an individual and their external world, further a stress response is elicited if the individual evaluates a potential stressful event as really being stressful (Lazarus and Folkman 1987). Lazarus defined two forms of appraisals. First, primary appraisal- the event is initially appraised as either irrelevant, positive, harmful and as a threat or harmful and as a challenge. Second, secondary appraisal- The evaluation of one's coping abilities and resources and whether they will be adequate to meet the future harm, challenge or threat of the event.

The resources may be physical, mental, personal or social. Broadly, the low stress perceived is associated with an individual's positive attitude, health and social support. Furthermore, research also exhibits that some events lead to a higher stress response than other events. Overload: A stressor occurring alone will be perceived as less stressful in comparison to when it is integrated with other existing stressors. Salient events: Important domain life stressors are more stressful in contrast to stressors that are in the peripheral domain. Ambiguous event: In ambiguous and unclear events an individual considerably spends more time and energy in deciphering as to which coping strategy is the best. Young adults with poor job control, pay-scale and role ambiguity in the workplace often result in a stress response. Uncontrollable events: Controlled and predicted stressors are usually interpreted as less stressful than uncontrollable arbitrary events. In these unprecedented times of pandemic where COVID-19 has taken up the world by storm has been appraised as a stressful life event by most individuals across countries. Psychological impact of COVID-19 on young adults has been visible due to increase in job unemployment, future uncertainty and goal hindrance.

\section{Relationship between Optimism and perceived stress}

The tendency to expect positive life outcomes and being optimistic towards the outlook of life may lead to reduced levels of perceived stress in one's life. On the other hand, increased levels of stress may lead an individual to have a negative or pessimistic attitude toward various life events. Numerous studies indicate a relationship between optimism and perceived stress. Radloff (1977) reported that perceived stress and optimism were negatively 
correlated. Kurdek and Siesky (1990) in their study found that the negative relationship between optimism and psychological distress was moderately high. Optimistic college students have been stated to experience less stress, depression and isolation than pessimistic college students when adapting to college life. (Scheier and Carver 1992).

\section{REVIEW OF LITERATURE}

Chang, E.C. (2002) examined the interactive model of optimism-pessimism and stress in predicting life satisfaction and psychological symptoms in a group of younger adults and a group of older adults. Findings indicated that optimism-pessimism and stress appraisal accounted for a significant amount of the variance in each of the adjustment measures, for each group.

Huan, V.S., et al. (2006) The study explored the role of optimism and gender on the students' perception of academic stress. Findings reported a negatively significant relationship between academic stress and optimism. Gender was found as an insignificant predictor of academic stress. There was no two-way interaction among optimism and gender of the subjects.

Reed, D.J. (2016) showed that optimism and coping flexibility were strongly correlated. Also, that optimism mediated the connection between coping flexibility and both perceived stress and life satisfaction.

Hayes, C.T., \& Weathington, B.L. (2007) The researchers evaluated stress, dispositional optimism, overall life satisfaction, and job burnout in restaurant managers. Stress and job burnout were found to be significantly related, although the association was not mediated by dispositional optimism.

Panchal, S., Mukherjee, S., \& Kumar, U. (2016) found the relationship between optimism, well-being, resilience and perceived stress among 181 undergraduates within the age group of 18-25 years. The results indicated optimism to have a significant positive relationship with well-being and resilience. Well-being was also found positively correlated with resilience.

Shaheen, F. (2015) studied life satisfaction and optimism in relation to psychological wellbeing among working and non-working women. Results indicated there was significant positive correlation between optimism and psychological well-being and between life satisfaction and psychological well-being.

Shaheen, H., \& Jahan, M. (2014) explored the relationship between stress and optimism and suicidal ideation among 200 adolescent students. Results found that there was a positive correlation between stress and suicidal ideation. A significant negative relationship between optimism and suicidal ideation was also found.

Putri, S.O. (2018) The purpose of the study was to find the relationship of optimism with stress coping in students who were completing their thesis. A sample of 56 students were taken using the random sampling technique. The result indicated a significant and positive relationship between optimism and coping stress.

Brissette, I., Scheier, M.F., \& Carver, C.S. (2002) explored the length to which social support and coping account for the association between more pronounced optimism and 
better adjustment to life's stressful situation. The findings suggested that optimists exhibited smaller increases in stress and depression during the study.

Rezaei, S.G., Mousavi, S.S.S., Safari, F., Bahrami, H. \& Menshadi, S.M.D. (2015) determined the relationship between optimism, pessimism, coping strategies and mental health in 367 subjects from Lorestan University. Findings indicated optimistic people to have more mental health because of following healthy behaviour and lifestyle and confirming problem-oriented coping strategies.

Shearman, E.K. (2008) The study purpose was to discern athletes and non-athletes and gender on optimism and life stress. The results backed the mentioned hypothesis that athletes with high levels of optimism experienced less stress. It also showed that high levels of optimism contributed to less psychological health problems.

Lai, J.C.L. (2009) investigated the effect of optimism on the relation between daily hassles and mental health among high school students of china. Through multiple linear regression analysis; it was seen that optimism works as a buffer for stress. It was also seen that optimists did better in handling hassles as compared to pessimists further proving the former.

McCann, C. (2014) investigated the relationship between dispositional optimism, perceived stress and recent life changes in the Irish population. The result indicated a significant negative relationship between dispositional optimism and perceived stress. The older population experienced less stress due to high levels of optimism compared to the younger people. It was also discovered that females showed lower levels of optimism and higher levels of stress and recent life changes in comparison to males. But the difference between gender in relation to dispositional optimism and recent life changes was not significant.

Anbumalar, C., et al. (2017) results revealed a significant negative relationship between perceived stress level and coping strategy. Also females were found to have higher levels of stress than male students, though the difference was not significant. Male participants had significant differences in stress coping strategies than female participants.

Nes, L.S., \& Segerstrom, S.C. (2006) The adjustment to varied stressors can be ascribed to optimism's effect on coping strategies. Dispositional optimism was found to be positively in relation with approach coping strategies which aim to eliminate and reduce stress and negatively related to avoidance coping strategies which look to avoid and withdraw from the stressor.

Pacheco, B., \& Kamble, S.V. (2016) studied the role of optimism in stress and coping with stress among the undergraduates of Goa. The results showed a prominent negative relation between optimism and mental disengagement, behavioural disengagement, focus on and venting of emotions, denial, and religious coping.

Chang, E. C., \& Sanna, L. J. (2003) Their results exhibited that optimism was significantly in relation with less depressive symptoms, physical symptoms, and less vulnerability to illness. Additionally, the LOT-R scores (optimism) were negatively related to the LES scores (stress). 
Singh, I., \& Jha, A. (2013) aimed to investigate the role of optimism in reducing anxiety, stress and enhancing academic achievements among the students from the field of medicine and engineering. Optimism was negatively related to anxiety and positively to academic achievement whereas there was a negative relation between anxiety and academic achievement. Medical students exhibited higher levels of anxiety and lower levels of optimism in comparison to engineering students, according to the researchers owing to the fact of medical students having more syllabus than the engineering students.

Arslan, G., \& Yildirim, M. (2020) studied whether meaning in life mediated the relationship between depressive symptoms and coronavirus stress and whether the mediating effect of meaning in life on depressive symptoms was moderated by optimism. Results indicated that the relationship among coronavirus stress and depressive symptoms were mediated by meaning in life and optimism and pessimism. Also, optimism mediated the relationship between meaning in life and depressive symptoms.

There is very little research that has been conducted on the association between optimism and stress. Therefore, the need to explore deeper into the realm of optimism and perceived stress and to the extent they are related.

\section{MATERIALS AND METHODS}

\section{Hypotheses}

- There is a significant negative correlation between optimism and perceived stress levels among young adults.

- There is no significant relationship between gender and perceived stress levels among young adults.

- There is no significant relationship between gender and optimism levels among young adults.

\section{Sample}

The sample of the present study consisted of 170 young adults (79 males and 91 females). Age of subjects ranged between 18 to 25 years, the mean age being 21.5 years. The technique employed for collecting the data was purposive sampling.

\section{Tools}

TOOL 1 - Perceived stress scale (Sheldon Cohen, 1983)

Perceived stress scale-10 (PSS; Cohen, Kamarack \& Marmelstein, 1983) was used to measure the extent to which subjects perceive that they have control over the stressful events in their lives. This scale consists of 10 items which are rated on a 5-point Likert-type scale from 0 (never) to 4 (very often). PSS scores are obtained by reversing scores of four items and six items in non-reversed direction, with higher scores indicating more perceived stress.

\section{TOOL 2 - Life Orientation Test- Revised (Scheir, Carver, \& Bridges, 1994)}

LOT-R was used to measure optimism. The test consists of 10 statements (3 positive statements, 3 negative statements and 4 filler items that are not scored). The subjects are asked to indicate the extent of their agreement with each of the items by choosing their appropriate response using a Likert scale, ranging from $0=$ strongly disagree to $4=$ strongly agree. 


\section{Procedure}

The responses for PSS-10 measuring perceived stress \& LOT-R measuring optimism were gathered through online google forms. The form consisted of a few preliminary questions like name, age and gender. Next, the subjects were informed about the purpose of the study and their consent were taken prior to participation in the study. Subjects were also informed that the confidentiality of the information provided will be maintained. Next, the instructions were given about how to fill the questionnaires. The questionnaires answered were collected and scored according to the manual. IBM SPSS software was used for statistically analysing scores.

\section{RESULT}

Table 1 : Correlations

\begin{tabular}{llll} 
& & scores of lotr & scores of pss \\
\hline scores of lotr & Pearson Correlation & 1 & $-.343^{* *}$ \\
\cline { 2 - 4 } & Sig. (1-tailed) & 170 & .000 \\
\cline { 2 - 4 } & $\mathrm{N}$ & $-.343^{* *}$ & 170 \\
\hline scores of pss & Pearson Correlation & .000 & 1 \\
\cline { 2 - 4 } & Sig. (1-tailed) & 170 & 170 \\
\cline { 2 - 4 } & $\mathrm{N}$ &
\end{tabular}

**. Correlation is significant at the 0.01 level (1-tailed).

Table 1 depicts the correlation between LOT-R and PSS measures for the entire sample. A significant negative correlation was found between Optimism and Perceived Stress. $[\mathrm{r}(170)=-.34, \mathrm{p}<0.01$, one-tailed $]$.

Descriptive statistics are shown in Table 2.

Table 2 : Descriptive Statistics

\begin{tabular}{l|l|l|l} 
& Mean & Std. Deviation & N \\
\hline scores pf pss & 19.76 & 6.254 & 170 \\
\hline scores of lotr & 13.72 & 3.505 & 170 \\
\hline
\end{tabular}

\section{Group Statistics}

\begin{tabular}{|c|c|c|c|c|c|}
\hline & gender & $\mathbf{N}$ & Mean & Std. Deviation & Std. Error Mean \\
\hline \multirow[t]{2}{*}{ scores of lotr } & Male & 79 & 14.25 & 3.283 & .369 \\
\hline & Females & 91 & 13.25 & 3.641 & .382 \\
\hline \multirow[t]{2}{*}{ scores pf pss } & Male & 79 & 17.97 & 6.495 & .731 \\
\hline & Females & 91 & 21.32 & 5.625 & .590 \\
\hline
\end{tabular}

Table 3: Independent sample test

\begin{tabular}{|c|c|c|c|c|c|c|c|c|c|c|}
\hline & & \multicolumn{2}{|c|}{$\begin{array}{l}\text { Levene's Test } \\
\text { for Equality of } \\
\text { Variances }\end{array}$} & \multicolumn{7}{|c|}{ t-test for Equality of Means } \\
\hline & & $\mathbf{F}$ & Sig. & $\mathbf{t}$ & df & $\begin{array}{l}\text { Sig. } \\
(2- \\
\text { tailed) }\end{array}$ & $\begin{array}{l}\text { Mean } \\
\text { Difference }\end{array}$ & $\begin{array}{l}\text { Std. Error } \\
\text { Difference }\end{array}$ & $\begin{array}{l}95 \% \text { Con } \\
\text { Interval } \\
\text { Difference } \\
\text { Lower }\end{array}$ & $\begin{array}{l}\text { fidence } \\
\text { of the } \\
\text { Upper }\end{array}$ \\
\hline \multirow[t]{2}{*}{$\begin{array}{l}\text { scores } \\
\text { of lotr }\end{array}$} & $\begin{array}{l}\text { Equal } \\
\text { variances } \\
\text { assumed }\end{array}$ & .756 & .386 & 1.870 & 168 & .063 & 1.000 & .535 & -.056 & 2.057 \\
\hline & $\begin{array}{l}\text { Equal } \\
\text { variances } \\
\text { not } \\
\text { assumed }\end{array}$ & & & 1.883 & 167.747 & .061 & 1.000 & .531 & -.048 & 2.049 \\
\hline scores & Equal & 2.226 & .138 & - & 168 & .000 & -3.344 & .929 & -5.179 & - \\
\hline
\end{tabular}




\section{Association of Optimism and Perceived Stress among Young Adults}

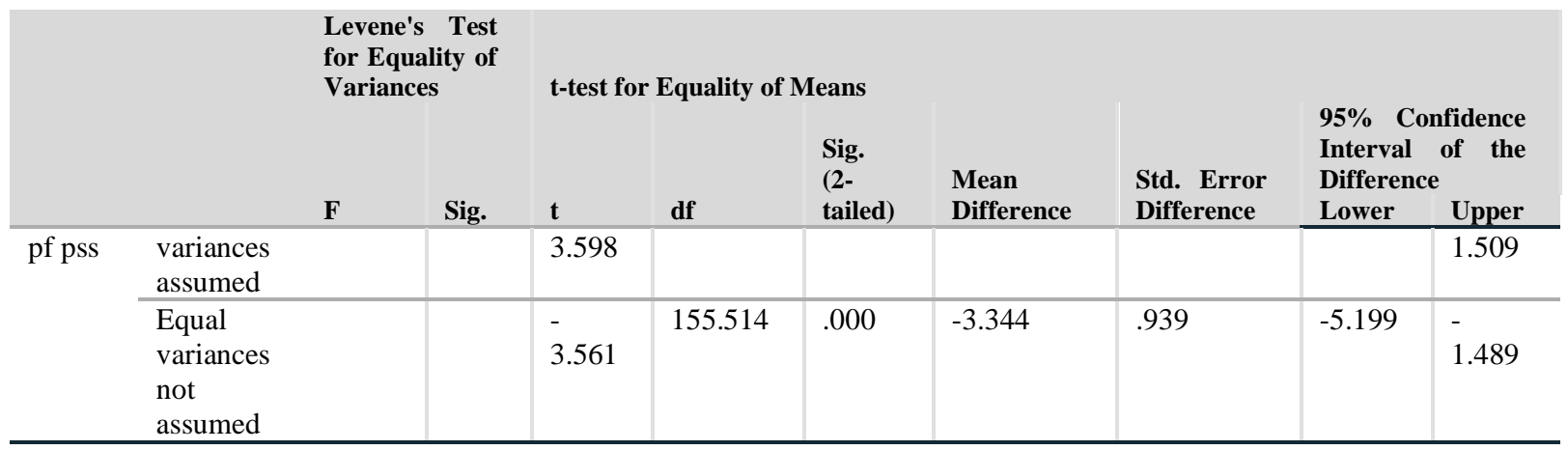

Independent sample t-test was used to explore the gender differences in LOT-R and PSS measures.

Table 3 depicts the result of the t-test.

Significant gender differences were found when male $(M=17.97), S . D=6.50)$ and females $(\mathrm{M}=21.32$, S.D $=5.63$ ) were measured on Perceived stress scale. [ $\mathrm{t}(170)=-3.60, \mathrm{p}<$ 0.05 , two-tailed ].

No significant gender differences were found when males $(\mathrm{M}=14.25, \mathrm{~S} . \mathrm{D}=3.28)$ and females ( $M=13.25$, S.D $=3.64$ ) were measured on the Life oriented test- Revised scale. [ $t$ $(170)=1.87, \mathrm{p}>0.05$, two-tailed $]$.

\section{DISCUSSION}

The purpose of the present research was to examine the relationship between optimism and perceived stress among young adults $(\mathrm{N}=170$, Males $=79$, Females $=91$ and age range $=18$ 25 years), as well as gender differences in optimism and perceived stress levels among the same sample. Correlational analysis was applied to explore the optimism-perceived stress relationship and an independent $t$ test was employed to understand the influence of gender on optimism and perceived stress.

The Null hypothesis of the research stated a negative correlation between optimism and perceived stress among young adults (Age 18-25 years). A significant negative correlation was found between optimism and perceived stress. Young adults with higher levels of optimism reported lower levels of stress. Therefore, the null hypothesis was accepted and our results were in accordance with the findings of a study conducted by Chang \& Sanna (2003) who revealed a significant negative association between life stress and levels of optimism in the population of adults. Furthermore, Brissette, Scheier, \& Carver (2002) also suggested that optimists exhibited smaller increases in stress and depression and greater increases in perceived social support during the study. To further elucidate the optimismperceived stress relationship, influence of gender on perceived stress levels were studied.

Our second null hypothesis proposed no significant gender differences in Perceived stress level among young adults. However, our findings reported that females scored significantly higher on Perceived stress level in comparison to men. Hence, our null hypothesis was rejected. This finding is consistent with the previous study conducted by McCann (2014) who reported that females perceived significantly higher amounts of stress than males. Another study by Almeida and Kessler (1998) found that women reported a higher prevalence of elevated days of distress and a lower prevalence of days without distress than men. Some factors which may be attributed as stressors in females life may be issues 
relating to safety in public places, gender related expectations such as being empathetic, family-oriented, taking care of their families. Another prevalent factor influencing the life of women may be the tradition of behaving in some way as society expects from women. Similarly, the role of gender on optimism was also investigated.

The third null hypothesis stated no significant gender differences in Optimism levels among young adults. The results revealed that the female optimism level did not differ significantly from the male optimism level. Our results are consistent with the findings of a McCann (2014) study that clarified that the gender gap was not important in relation to dispositional optimism. Huan, Yeo, Ang \& Chong (2006) stated that no two-way relationships were identified between the participants' optimism and gender.

The sample considered was from the range of 18-25 years. The transition from school to college is a new and evolving phase in the adult's life, which can be very demanding and challenging for an individual. In this process of transition adults learn to become independent and autonomous and make efforts to fulfill their dreams, goals and aspirations. The responsibilities, obligations and expectations of family and society also increases, and often occurs in addition to the former relationship formation (personal and social relationships). Such demanding and constantly changing roles and situations can be perceived as a stressful event in an individual's life.

\section{CONCLUSION}

The present research concluded that optimism is negatively associated with perceived stress among young adults. As expected from the previous review of literature, the level of optimism affects the perception of stress among young adults. Though the moderate correlation between optimism and perceived stress could reflect the role of other variables in perception of stress such as social support, coping mechanisms, recent life changes, optimism, self-esteem which needs to be further investigated. It is also concluded that female young adults were found to perceive higher levels of stress than male young adults, which is in accordance with the previous research. While the average scores of male and female differed in relation to optimism, these differences were not significant. Thus, gender differences in optimism need to be further explored.

\section{Limitations And Implications}

The research has certain limitations. First, apart from optimism we did not consider other variables which could affect perception of stress such as personality differences, social support, coping mechanisms, and recent life changes. Second, the sampling method used in no way ensured that the sample considered is truly random or representative of the populations. Third, only self-report measures were used to gather all information from the subjects.

There are certain practical implications of the present research. As the research indicated significant association between optimism and perceived stress among young adults. Workshops and classes should be conducted in schools, colleges, offices to help young adults improve optimism levels and learn to manage stress. Counseling services need to be increased, to help mitigate the level of stress facing young adults. Focus should be made on improving optimism levels as optimism has been found to have a positive impact on physical health. 
REFERENCES

Abramson, L. Y., Seligman, M. E., \& Teasdale, J. D. (1978). Learned helplessness in humans: Critique and reformulation. Journal of Abnormal Psychology, 87, 49-74.

Almeida, D. M., \& Kessler, R. C. (1998). Everyday stressors and gender differences in daily distress. Journal of Personality and Social Psychology, 75, 670-680.

Anbumalar, C., Dorathy, A.P., Jaswanti, V.P., Priya, D., \& Reniangelin, D. (2017). Gender Differences in Perceived Stress Levels and Coping Strategies among College Students. The International Journal of Indian Psychology. ISSN 2348-5396 (e) | ISSN: 2349-3429 (p) Volume 4, Issue 4, DIP: 18.01.103/20170404 DOI: 10.25215/0404.103.

Arslan, G., \& Yildirim, M. (2020). Coronavirus Stress, Meaningful Living, Optimism, and Depressive Symptoms: A Study of Moderated Mediation Model.

Aspinwall, L. G., \& Taylor, S. E. (1992). Modeling cognitive adaptation: A longitudinal investigation of the impact of individual differences and coping on college adjustment and performance. Journal of Personality and Social Psychology, 63, 9891003

Brissette, I., Scheier, M. F., \& Carver, C. S. (2002). The Role of Optimism in Social Network Development, Coping, and Psychological Adjustment During a Life Transition. Journal of Personality and Social Psychology 2002, Vol. 82, No. 1, 102 111.

Chang, E. C., \& Sanna, L. J. (2003). Optimism, Accumulated Life Stress, And Psychological and Physical adjustment: Is it always adaptive to expect the best? Journal of Social and Clinical Psychology, Vol. 22, No. 1, 2003, pp. 97-115.

Chang, E.C. (2002). Optimism-Pessimism and Stress Appraisal: Testing a Cognitive Interactive Model of Psychological Adjustment in Adults. Cognitive Therapy and Research, Vol. 26, No. 5, October 2002, pp. 675-690.

Fontaine, K.R., Manstead, A.S., \& Wagner, H. (1993). Optimism, perceived control over stress, and coping. European Journal of Personality, Vol. 7,267-281 (1993).

Hayes, C.T., \& Weathington, B.L. (2007). Optimism, Stress, Life Satisfaction, and Job Burnout in Restaurant Managers. The Journal of Psychology, 2007, 141(6), 565-579.

Huan, V.S., Yeo, L.S., Ang, R.P., \& Chong, W.H. (2006). The influence of dispositional optimism and gender on adolescents' perception of academic stress. ADOLESCENCE, Vol. 41, No. 163, Fall 2006 Libra Publishers, Inc., 3089C Clairemont Dr., PMB 383, San Diego, CA 92117.

Kurdek, L. A., \& Siesky, G. (1990). The nature and correlates of psychological adjustment in gay men with AIDS-related conditions. Journal of Applied Social Psychology, 20(10), 846-860.

Lai, J. C. L. (2008). Dispositional optimism buffers the impact of daily hassles on mental health in Chinese adolescents. Personality and Individual Differences 47 (2009) 247-249.

Lazarus, R. S., \& Folkman, S. (1987). Transactional theory and research on emotions and coping. European Journal of Personality, 1 : 141-70.

McCann, C. (2014). The relationship between dispositional optimism, recent life changes and perceived stress in Irish adults.

Nes, L. S., \& Segerstrom, S. C. (2006). Dispositional Optimism and Coping: A MetaAnalytic Review. Personality and Social Psychology Review 2006, Vol. 10, No. 3, 235-251.

Ogden, J. (2004). Health Psychology: A textbook 3rd edition. Open University Press McGraw-Hill Education. 
Pacheco, B., \& Kamble, S. V. (2016). The Role of Optimism in Stress and Coping of Undergraduate Students in Goa. The International Journal of Indian Psychology ISSN 2348-5396 (e) | ISSN: 2349-3429 (p) Volume 3, Issue 2, No.5, DIP: 18.01.080/20160302 ISBN: 978-1-329-87724-5.

Panchal, S., Mukherjee, S., \& Kumar, U. (2016). Optimism in Relation to Well-being, Resilience, and Perceived Stress. International Journal of Education and Psychological Research (IJEPR) Volume 5, Issue 2, June 2016.

Passer, M.W., \& Smith, R.E. (2013). Psychology: The Science of Mind and Behaviour. New Delhi: Tata McGraw-Hill.

Psychology: Textbook for class XII. NCERT.

Putri, S.O. (2018). Relationship Between Optimism and Stress Coping on Students who are Completing the Thesis. International Journal of Science and Research (IJSR) Volume 7 Issue 9, September 2018.

Radloff, L. S. (1977). The CES-D Scale: A self-report depression scale for research in the general population. Applied Psychological Measurement, 1(3), 385-401.

Reed, D.J. (2016). Coping with occupational stress: The role of optimism and coping flexibility. Psychology Research and Behavior Management 2016:9 71-79.

Rezaei, S.G., Mousavi, S.S.S., Safari, F., Bahrami, H. and Menshadi, S.M.D. (2015) Study of Relationship between Optimism, Pessimism and Coping Strategies with Mental Health among University Students of Lorestan. Open Journal of Social Sciences, 3, 190-195. http://dx.doi.org/10.4236/jss.2015.312021

Scheier, M. F., \& Carver, C. S. (1985). Optimism, coping, and health: Assessment and implications of generalized outcome expectancies. Health Psychology, 4, 219-247.

Scheier, M. F., \& Carver, C. S. (1992). Effects of optimism on psychological and physical well-being: Theoretical overview and empirical update. Cognitive Therapy and Research, 16, 201-228.

Scheier, M. F., Carver, C. S., \& Bridges, M. W. (1994). Distinguishing optimism from neuroticism (and trait anxiety, self-mastery, and self-esteem):A revaluation of the Life Orientation Test. Journal of Personality and Social Psychology, 67, 1063-1078.

Segerstrom, S. C., Castańeda, J. O., \& Spencer, T. E. (2003). Optimism effects on cellular immunity: Testing the affective and persistence models. Personality and Individual Differences, 35, 1615-1624.

Seligman, M.E.P. (2002). Authentic happiness: Using the new positive psychology to realize your potential for lasting fulfillment. New York: Free Press.

Shaheen, F. (2015).A Study of Life Satisfaction and Optimism in Relation to Psychological Well-Being Among Working and Non-Working Women. International Journal of Education and Psychological Research (IJEPR) Volume 4, Issue 4, December 2015.

Shaheen, H., \& Jahan, M. (2014). The Role of Optimism in Experience of Student Stress and Suicidal Ideation. IOSR Journal of Humanities and Social Science (IOSR-JHSS) Volume 19, Issue 11, Ver. VI (Nov. 2014), PP 23-34 e-ISSN: 2279-0837, pISSN:2279-0845.

Shearman, E. K. (2008). Comparison of Optimism Levels and Life Stress Levels Among NCAA Division I Athletes and Non-Athletes. Electronic Theses and Dissertations. 86.

Singh, I., \& Jha, A. (2013). Anxiety, Optimism and Academic Achievement among Students of Private Medical and Engineering Colleges: A Comparative Study. Journal of Educational and Developmental Psychology; Vol. 3, No. 1; 2013 ISSN 1927-0526 E-ISSN 1927-0534, Published by Canadian Center of Science and Education.

Taylor, S.E. (2012). Health psychology 7th Edition. Tata McGraw-Hill Edition.

(c) The International Journal of Indian Psychology, ISSN 2348-5396 (e) | ISSN: 2349-3429 (p) | 2107 
Association of Optimism and Perceived Stress among Young Adults

\section{Acknowledgement}

The author(s) appreciates all those who participated in the study and helped to facilitate the research process.

\section{Conflict of Interest}

The author(s) declared no conflict of interest.

How to cite this article: Joshi R.\& Joshi P. (2021). Association of Optimism and Perceived Stress among Young Adults. International Journal of Indian Psychology, 9(2), 2098-2108. DIP:18.01.207.20210902, DOI:10.25215/0902.207 